\title{
Studi Pengukuran Koefisien Atenuasi Material Zincalume Sebagai Perisai Radiasi Gamma
}

\section{Ruly Gumilar ${ }^{1}{ }^{*}$, Annisa Nur Fitriani ${ }^{1}$, Tera Ummutafiqoh ${ }^{1}$, M. Nurul Subkhi ${ }^{1}$, Yudha Satya Perkasa ${ }^{1}$}

1 Jurusan Fisika Fakultas Sains dan Teknologi UIN Sunan Gunung Djati Bandung , Jl. AH Nasution no. 105 Bandung, Indonesia, 40614

*Ruly Gumilar. E-mail: rulygumilar@gmail.com

Telp/hp: 087760949422

\begin{abstract}
ABSTRAK
Radiasi merupakan energi yang dipancarkan dalam bentuk partikel atau gelombang dari suatu sumber radioaktif. Partikel tersebut tidak dapat terlihat secara kasat mata diantaranya partikel alfa $(\alpha)$, beta $(\beta)$ dan gamma $(\gamma)$. Sedangkan jika suatu partikel berinteraksi secara langsung dengan tubuh makhluk dapat menyebabkan terjadinya ionisasi bahkan mutasi yang akan berdampak negatif terhadap kesehatan. Sehingga dalam makalah ini akan dilakukan pengukuran koefisien atenuasi material $(\mu m)$ zincalume sebagai perisai radiasi, material tersebut mudah ditemukan karena sudah diproduksi dan digunakan secara luas dalam bidang konstruksi. Pengukuran dilakukan dengan simulasi menggunakan program transfort monte carlo MCNPX, meliputi detektor $\mathrm{NaI}(\mathrm{Tl})$ dengan terlebih dahulu diuji efisiensi absolutnya dan dibandingkan antara eksperimen dan simulasi, kemudian material perisai di investigasi dengan ketebalan berbeda dari $2 \mathrm{~cm}-10 \mathrm{~cm}$ menggunakan sumber radioaktif ${ }^{60} \mathrm{Co}$. Hasil pengukuran menunjukan koefisien attenuasi meningkat dengan bertambahnya ketebalan perisai, intensitas radiasi dapat berkurang hingga $95.58 \%$ dengan ketebalan perisai $5 \mathrm{~cm}$. Material zincalume dapat digunakan sebagai perisai radiasi gamma energi rendah dengan ketebalan
\end{abstract}


$2 \mathrm{~cm}$ dengan daya serap radiasi lebih dari setengahnya.

Kata Kunci : Radiasi; Zincalume;Atenuasi; Perisai; MCNPX

\begin{abstract}
Radiation is energy that is emitted in the particles or waves of radioactive source. The particles can not be seen by naked eye among the alpha particle $(\alpha)$, beta $(\beta)$ and gamma $(\gamma)$. Meanwhile, if a particle interacts directly with the body also can cause ionization even mutations that will have a negative impact on health. Thus, in this paper will be measured attenuation coefficient material $(\mu m)$ zincalume as radiation shields, the material is easy to find because it is produced and used widely in the construction field. Measurements were performed by simulation using the program transfort monte carlo MCNPX, includes detectors $\mathrm{NaI}(\mathrm{Tl})$ to advance in test the efficiency absolute and comparison between experiment and simulation, then material shield in the investigation of varying thickness of $2 \mathrm{~cm}-10 \mathrm{~cm}$ using a radioactive source ${ }^{60} \mathrm{Co}$. The measurement results showed attenuation coefficient increases with the thickness of the shield, the radiation intensity can be reduced by $95.58 \%$ with a thickness of $5 \mathrm{~cm}$ shield. Zincalume material can be used as low-energy gamma radiation shield with a thickness of $2 \mathrm{~cm}$ with the absorption of radiation by more than half.
\end{abstract}

Keywords : Radiation; zincalume; attenuation; Shielding; MCNPX 


\section{Pendahuluan}

Radioisotop merupakan suatu inti yang tidak stabil, secara spontan akan berubah menjadi inti atom lain yang lebih stabil berupa partikel alpha $(\alpha)$, partikel beta ( $\beta$ ) atau sinar gamma dipancarkan tersebut sinar- $\gamma$ memiliki energi paling tinggi, didefinisikan mulai dari $10 \mathrm{keV}$. Sehingga akan berbahaya jika radiasi sinar- $\gamma$ terpapar secara langsung pada lingkungan makhluk hidup, khususnya pada manusia. [1]Paparan radiasi sinar- $\gamma$ secara langsung dengan dosis ekuivalen lebih dari $60 m S v$ terhadap tubuh manusia dapat menyebabkan terjadinya seperti luka bakar, kanker dan mutasi genetik bahkan berujung pada kematian. [10] Karakteristik dari radiasi sinar- $\gamma$ membentuk spektrum elektromagnetik yang paparannya tidak dapat terlihat, sehingga diperlukan perisai untuk memproteksi radiasi agar tidak terpapar pada lingkungan.

Terdapat tiga kemungkinan kejadian akibat interaksi radiasi dengan materi yaitu:

- Efek fotolistrik kemungkinan terjadi jika materi bernomor massa tinggi.

- Hamburan compton kemungkinan terjadi jika materi bernomor massa rendah.

- Produksi pasangan kemungkinan terjadi jiak enrgi radiasi lebih dari $1 \mathrm{MeV}$. [6]

Ketiga kejadian tersebut akan terjadi pada material perisai karena energi yang dipancarkan oleh sumber radiasi bervariasi. dengan memancarkan energi radiasi.

Radiasi yang dipancarkan tersebut dapat
Perisai untuk radiasi sinar- $\gamma$ membutuhkan material dengan nomor atom dan densitas yang tinggi, timbal $(\mathrm{Pb})$ material yang memiliki kriteria tersebut, namun material ini mahal dan penggunaannya terbatas atau sulit didapatkan.[2] Sehingga dalam studi ini memanfaatkan material yang diproduksi secaara luas dan tidak terlalu mahal yaitu zincalume

sebagai perisai radiasi sinar- $\gamma$. Untuk menggunakan material periasai sebelumnya harus diketahui

kemampuan material dalam pelemahan radiasi, dikenal sebagai koefisien attenuasi material ${ }_{(\mu}^{m}$ ) .

[9]

\section{Bahan dan Metode}

\subsection{Validasi Model Detektor MCNP}

Validasi model detektor $\mathrm{NaI}(\mathrm{Tl})$ dilakukan dengan melakukan perhitungan efisiensi absolut detektor. Model yang disimulasikan harus diketahui efisiensi absolutnya terutama dalam 
pengukuran radioaktivitas.[4] Efisiensi absolut dihitung menggunakan persamaan (1) sebagai

$$
\varepsilon_{a b s}=\frac{N c}{N s}
$$

dimana $N c$ adalah jumlah cacah per detik yang terdeteksi oleh detektor (CPS), Ns adalah jumlah jurnlah radiasi yang dipancarkan oleh sumber (Aktivitas). Model detektor $\mathrm{NaI}(\mathrm{Tl})$ disimulasikan dengan program transport Monte Carlo MCNPX.2.6.0, program yang dikhususkan untuk menyimulasikan setiap model interaksi radiasi dengan materi berikut:

menggunakan metode Monte Carlo. Geometri model detektor ditunjukan oleh Gambar 1. Parameter model detektor sesuai dengan detektor yang berada di Laboratorium Nuklir dan Energi Jurusan Fisika Fakultas Sains dan Teknologi UIN Sunan Gunung Djati Bandung dari manufaktur Sconix Hollan model 38 B 51/2$\mathrm{X}$ ditunjukan oleh Tabel 1.

Tabel 1. Parameter detektor NaI(Tl) merk Scionix Holland

\begin{tabular}{clll}
\hline $\mathbf{N O}$ & \multicolumn{1}{c}{ Komponen } & Densitas $(\mathrm{g} / \mathbf{c c})$ & Dimensi (cm) \\
\hline $\mathbf{1}$ & Kristal NaI(Tl) & 3.67 & 3.8 (diameter) \\
\hline & & & 5.1 (tinggi) \\
\hline $\mathbf{2}$ & Lapisan $\mathrm{Al}_{2} \mathrm{O}_{3}$ & 3.97 & 0.1 \\
\hline $\mathbf{3}$ & Penutup $\mathrm{Al}$ & & 4.45 (diameter) \\
\hline & & 0.04 (tinggi) \\
\hline $\mathbf{4}$ & Vakum (Kristal-Window) & 0.21
\end{tabular}

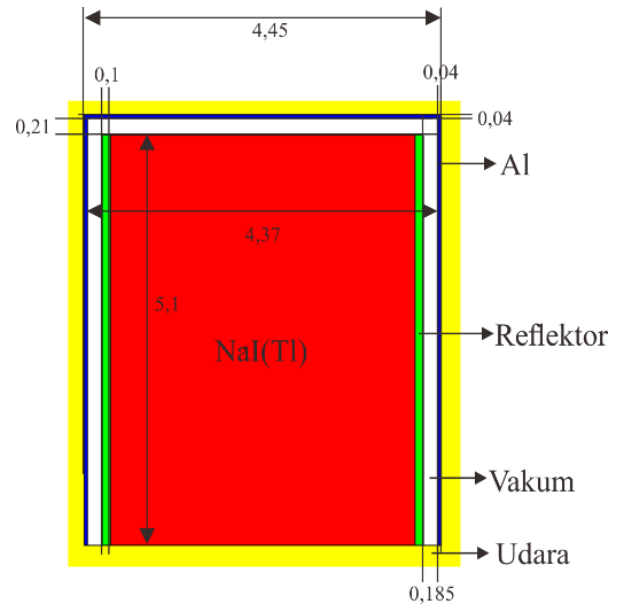

Gambar 1. Geometri model detektor NaI(Tl) dengan MCNPX2.6.0 
Respon dari model detektor yang disimulasikan ditentukan dengan definisi input tally rata-rata tinggi pulsa radiasi sinar- $\gamma$ ari sumber terdeteksi yaitu tally F8:P [7]. Untuk mendapatkan spektrum energi yang di inginkan memanfaatkan tally khusus Gaussian Energy Broading (GEB)

mengikuti persamaan (2) sebagai berikut: $F W H M=a+b \sqrt{E+c E^{2}}$

(2) dengan konstanta $a=0, b=$ $0.05086, c=0.30486$ dan $E$ adalah energi sumber. [3] Nilai cacahan pada setiap bin eneri ditentukan dengan nilai ketidakpastiannya, rentang bin energi dari 0-2000

$\mathrm{keV}$. Model sumber radiasi menggunakan model sumber titik isotropik dari ${ }^{60} \mathrm{Co}$ dengan energi

emisi sinar- $\gamma 1173 \mathrm{keV}$ dan $1333 \mathrm{keV}$, banyak partikel yang disimulasikan yaitu satu milyar partikel (NPS 10E9). Simulasi dilakukan menggunakan PC (Personal
Computer) dengan spesifikasi prosesor Intel(R) Core(TM) i3-3110M @ 2.40 GHz, RAM (Random Array Memory) 2 GB dan sistem operasi Windows 7. Efisiensi absolut dari simulasi model detektor terhitung dibandingkan dengan efisiensi absolut hasil eksperimen, dimana eksperimen menggunakan sumber ${ }^{60} \mathrm{Co}$ aktivitas $74 \mathrm{kBq}$ dari manufaktur Eckert dan Ziegler.

\subsection{Perhitungan Koefisien Attenuasi Material}

Perhitungan dilakukan dengan simulasi dari detektor $\mathrm{NaI}(\mathrm{Tl}) \quad$ menggunakan MCNPX2.6.0 yang telah divalidasi. Performa koefisien attenuasi material zinculame di investigasi melauli perbedaan ketebalan yang digunakan sebagai perisai radiasi dari ketebalan 2-10 $\mathrm{cm}$ dan perubahan pulsa cacahan akibat perbedaan ketebalan. Struktur elemen zinculame disajikan pada Tabel 2. Sebagai berikut:

Tabel 2. Parameter material zincalume densitas 8.196 g.cm ${ }^{-3}$

\begin{tabular}{ccc}
\hline No & Elemen & Fraksi Massa (\%) \\
\hline $\mathbf{1}$ & $\mathrm{Zn}$ & 55 \\
\hline $\mathbf{2}$ & $\mathrm{Al}$ & 43 \\
\hline $\mathbf{3}$ & $\mathrm{Si}$ & 2 \\
\hline
\end{tabular}


diameter $30 \mathrm{~cm}$ agar menghindari paparan radiasi sumber secara langsung pada detektor. Model perhitungan koefisien attenuasi material zincalume seperti Gambar 2.

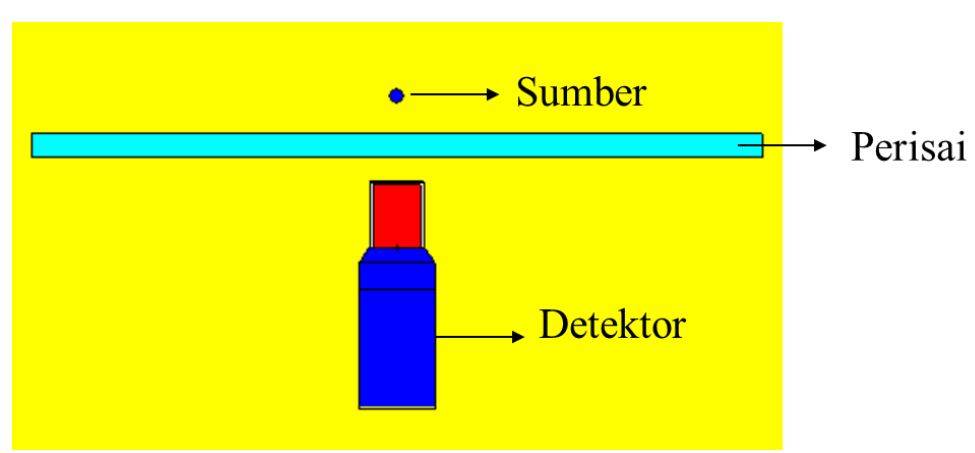

Gambar 2. Model geometri dengan MCNPX2.6.0 
Pencacahan pulsa radiasi yang diperhitungkan pada material perisai dan detektor. Perhitungan untuk mendapatkan koefisien attenuasi ditentukan dengan metode hukum Beer-Lambers sebagai berikut.[8] $\mu . x=\ln \left(\frac{I_{0}}{I}\right)$

dimana $\mathrm{I}_{0}$ dan $\mathrm{I}$ adalah intensitas radiasi sumber dan intensias setelah melalui perisai, $\mu\left(\mathrm{cm}^{-1}\right)$ adalah koefisien attenuasi tidak bergantung jenis material dan $\mathrm{x}$ (cm) adalah ketebalan perisai. Untuk mendapatkan koefisien attenuasi material menggunakan persamaan (4) sebagai berikut: $\mu_{m}=\left(\frac{\mu}{\rho}\right)$

dimana $\rho\left(\mathrm{g} . \mathrm{cm}^{-3}\right)$ adalah densitas material perisai dan material $\mu_{m}\left(\mathrm{~cm}^{2} \mathrm{~g}^{-1}\right)$ adalah koefisien atenuasi material.

\section{Hasil dan Pembahasan}

Hasil simulasi untuk pengukuran efesiensi absolut model detektor dan eksperimen masing-masing 9.9131E-2 $\% \pm 0.02 \%$ dan 1.796E-2\%. Efisiensi absolut detektor dari hasil eksperimen lebih kecil daripada simulasi dengan rasio sebesar $4.52 \%$, rasio tersebut dapat disebabkan karena beberapa faktor seperti tidak sesuainya spesifikasi geometri detektor yang disumulasikan dengan detektor ril karena bagian dalam detektor tidak dapat dibuka sehingga tidak dapat melihat lebih detail bagian dalam detektor, kemudian ketika eksperimen dilakukan sumber yang gunakan dengan jarak $5 \mathrm{~cm}$ dari detektor, paparan radiasi akan tersebar kesegala arah (isotropik) tidak fokus pada detektor sehingga intensitas radiasi terdeteksi lebih kecil daripada intensitas terpancar, sesuai dengan persamaan (1) tentu akan mengurangi efisiensi detektor, selanjutnya faktor penurunan efisiensi dari detektor $\mathrm{NaI}(\mathrm{Tl})$ mengingat karakteristik dari krsital $\mathrm{NaI}(\mathrm{Tl})$ yang sensitif terhadap cahaya, sedangkan keadaan ruangan laboratorium sangat terang tidak ada filter cahaya.

Validasi model detektor jika dilihat dari spektrum energi terdeteksi seperti pada Gambar 3. Radiasi yang dipancarkan oleh sumber ${ }^{60} \mathrm{Co}$ diserap seluruhnya oleh elektron-elektron pada kristal detektor $\mathrm{NaI}(\mathrm{Tl})$ maka terjadi interaksi foton dengan material yang disebut efek fotolistrik. Efek fotolistrik menghasilkan puncak energi (photopeak) pada daerah energi $1173 \mathrm{keV}$. Apabila sinar- $\gamma$ berinteraksi dengan sebuah elektron bebas atau yang terikat lemah, maka sebagian energi sinar- $\gamma$ akan diserap oleh elektron dan terjadi hamburan Compton. Titik batas antara hamburan Compton dan efek fotolistrik menghasilkan puncak energi disebut Compton Edge terjadi pada daerah energi $800 \mathrm{keV}$. Kemudian pada daerah energi $240 \mathrm{keV}$ terjadi Backscatter dimana foton dihamburkan keluar dikembalikan oleh reflektor kedalam detektor . Selain itu interaksi sinar- $\gamma$ menyebabkan terjadinya 
http://ejournal.upi.edu/index.php/wafi

produksi pasangan pada daerah energi 1350

$\mathrm{keV}$ melalui inti atom sehingga terbentuknya pasangan positron dan elektron. Karena interaksi tersebut maka jumlah sinar- $\gamma$ yang berhasil mengenai kristal detektor akan berkurang.

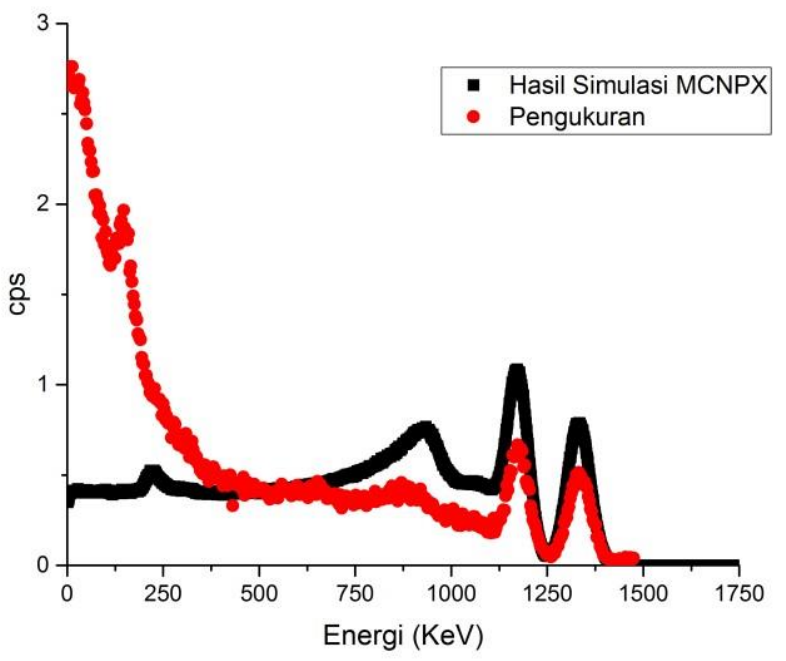

Gambar 3. Spektrum deteksi radiasi terhadap energi

Validasi model detektor dengan MCNPX2.6.0 meskipun menunjukan hasil yang berbeda dengan eksperimen, model detektor dapat digunakan untuk studi Perhitungan koefisien attenuasi material terhadap radiasi sinar- $\gamma$ telah dilakukan dengan menggunakan ketebalan yang berbeda hasil dari setiap pengukuran masing-masing disajikan pada Tabel 3. perhitungan koefisien attenuasi material karena niali relatif error sangat kecil atau kurang dari $1 \%$. 
http://ejournal.upi.edu/index.php/wafi

Tabel 3. Koefisien attenuasi material zincalume terhadap radiasi

\begin{tabular}{cccc}
\hline No & $\boldsymbol{x}(\mathbf{c m})$ & $\mu_{\cdot_{m}}\left(\mathrm{~cm}^{2} \cdot \mathrm{g}^{-1}\right)$ & Relatif error $\pm(\boldsymbol{\%})$ \\
\hline $\mathbf{1}$ & 2 & $4.16 \mathrm{E}-01$ & 0.03 \\
\hline $\mathbf{2}$ & 4 & $5.17 \mathrm{E}-01$ & 0.04 \\
\hline $\mathbf{3}$ & 6 & $6.22 \mathrm{E}-01$ & 0.06 \\
\hline $\mathbf{4}$ & 8 & $7.29 \mathrm{E}-01$ & 0.09 \\
\hline $\mathbf{5}$ & 10 & $8.36 \mathrm{E}-01$ & 0.14 \\
\hline Rata-rata & & $6.24 \mathrm{E}-01$ & 0.072 \\
\hline
\end{tabular}

Hasil pengukuran menunjukan koefisien attenuasi semakin meningkat dengan bertambahnya ketebalan sesuai dengan intensitas radiasi yang terdeteksi oleh detektor semakin menurun, hal tersebut terjadi karena radiasi yang dipancarkan sumber tertahan dan tidak dapat menebus material perisai dengan densitas cukup tinggi $8.196{\mathrm{~g} . \mathrm{cm}^{-3}}^{-}$. Dari rata-rata koefisien attenuasi material terhitung dapat diketahui dengan ketebalan perisai $2 \mathrm{~cm}$ intensitas radiasi sumber yang lolos hanya $28 \%$. Intensitas pulsa radiasi terdeteksi semikin tinggi dengan miningkatnya koefisien attenuasi material ditunjukan pada Gambar 4. Pada titik terendah material mampu melemahkan intensitas radiasi lebih dari $83 \%$ dapat dilihat dari intensitas pulsa sumber yang datang sebesar $0.45 \mathrm{cps}$

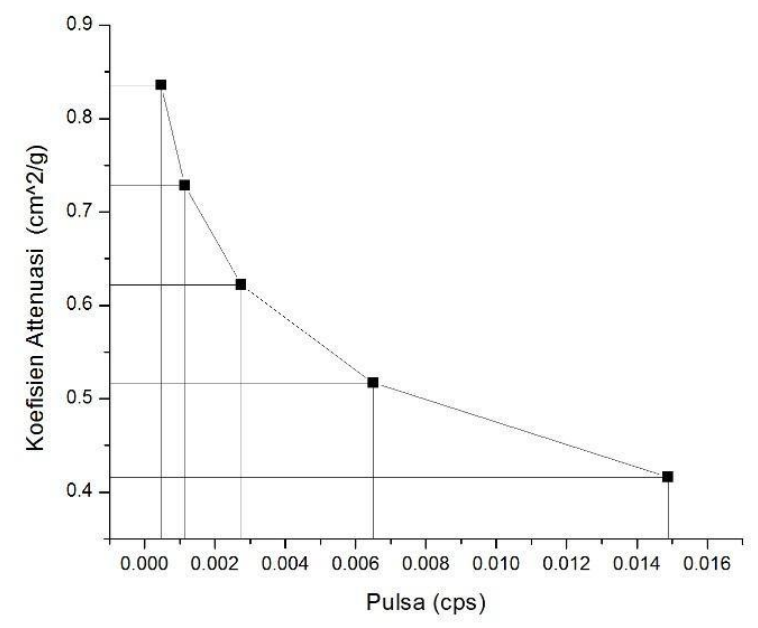

Gambar 4. Penurunan intensitas pulsa terdeteksi terhadap koefisien attenuasi material 


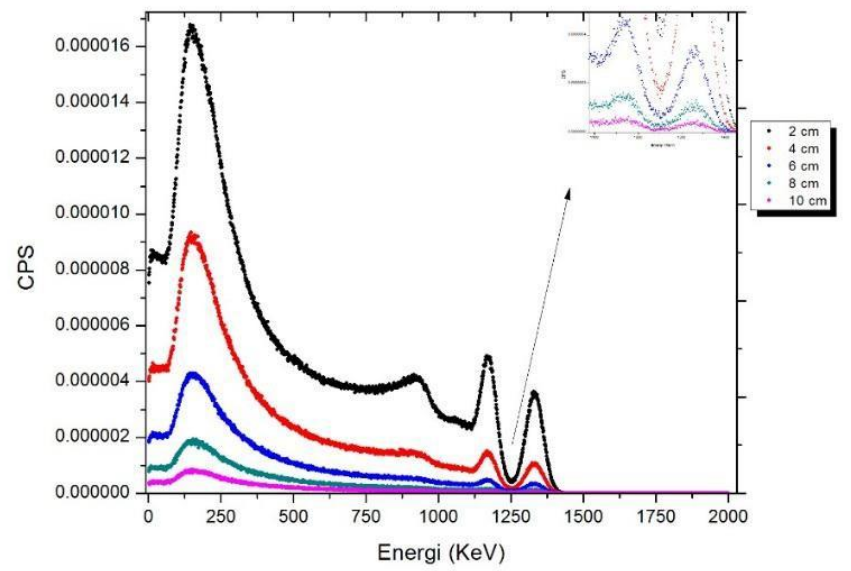

Gambar 5. Penurunan spektrum pulsa radiasi terhadap energi

Dapat terlihat pada Gambar 5. spektrum pulsa gejala fisis yang terjadi persis seperti spektrum pada pengukuran efisiensi absolut detektor, hanya Gambar 5. menunjukan pelemahan hingga pada ketebalan $10 \mathrm{~cm}$ dari energi $250 \mathrm{keV}$ pulsa terdeteksi mendekati nol yaitu 1E-9 cps hingga 9E-9 cps. Hal tersebut menunjukan material zincalume layak untuk digunakan sebagai perisai radiasi.

\section{Simpulan}

Efisiensi absolut model detektor dipengaruhi oleh ketidak akuratan geometri model namun tidak menjadi kendala selama nilai relatif error kurang dari 1\%. Material zincalume dapat digunakan sebagai perisai dengan ketebalan minimal $5 \mathrm{~cm}$ yang kemampuan pelemahan radiasi sinar-sebesar $95.58 \%$ untuk sumber radioaktif ${ }^{60} \mathrm{Co}$ dengan aktivitas $74 \mathrm{kBq}$.

\section{Ucapan Terima Kasih}

Terima kasih kepada laboran yang selalu memberikan bantuan dalam akses dan kebutuhan laboratorium, sehingga dapat diselesaikannya studi ini.

\section{Referensi}

[1] Lamarsh, J.R., Baratta, J.A. eds. (1982). Introduction to Nuclear Enginnering. Reading, Mass.: Addison- Wesley. Shirmadi, S.P., Shamsae., M, Naserepour., M (2013). Comparison of Photon Attenuation

Coefficients of Various Barite Concretes and Lead by MCNP Code, XCOM and Experimental

DataNew Ways to Make Microcircuits Smaller. Annals of Nuclear Energy, 55: 288-291.

[3] Salgado, C.M., at all. (2012). Validation of a NaI(Tl) Detector's Model Developed with

MCNP-X Code. Progress in Nuclear Energy, 59: 19-25.

[4] Tekin., H.O. (2016). MCNP-X Monte 
http://ejournal.upi.edu/index.php/wafi

Carlo Code Application for Mass Attenuation Coefficients of Concrete at Different Energies by Modeling 3x3 Inch $\mathrm{NaI}(\mathrm{Tl})$ Detector and Comparison with XCOM and Monte Carlo Data. Tscience and Technology of Nuclear Istallation, 2016: 1-7.

Schwarz, A., Schwarz, R., Carter, L. (2008). MCNP/MCNPX Visual Editor Computer Code Manual, this manual applies to MCNPX version 2.6.0. New Mexico: Los Almos National Laboratory.

[6] Alatas, Z., dkk. eds. (2013). Buku Pintar Nuklir. JKT: BATAN.

[7] Fitriani, A.N. (2016). : Penentuan Efisiensi Detektor NaI(Tl) Menggunakan Metode Monte Carlo Software MCNPX,
Skripsi, Dept. Fisika, Universitas Islam

Negeri Sunan Gunung Djati Bandung.

Ummuttaufiqoh, T. (2016). : Desain Ketebalan Perisai untuk Sumber Radiasi Gamma pada Detektor Sintilasi dengan Menggunakan MCNPX, Skripsi, Dept. Fisika, Universitas Islam Negeri Sunan Gunung Djati Bandung.

Pleitt, J.J. (2012). Determination of Linear Attenuation Coefficients of Chemically Bonded Phosphate Ceramics. Meng Thesis, Department of Mining and Nuclear Engineering, Missouri University of Science and Technology.

[10] BATAN.(8 Desember 2016). sumber URL http://www.batan.go.id/ensiklopedi/08/01/ 02/03/08-01-02-03.html. 